At Singapore the eclipse was very well seen, totality occurring about $12.5 \mathrm{I}$ p.m. An interesting series of observations of the temperature variations were made there. The reading before eclipse in full sun was $143^{\circ}$, which fell during totality to $8 \mathrm{I}^{\circ}$, which was 2 degrees below the normal shade temperature.

\section{RECENT WORK OF THE U.S. WEATHER BUREAU. 1}

THE Report of the Weather Bureau for the year ended 1 June 30, 1899, which appeared at the end of last year, extends over two volumes. The first, which includes the usual administrative report and the climatological statistics of the United States Weather Service, is a volume of the ordinary dimensions, while the second and special volume, being part vi. of the whole report, is devoted to Prof. Bigelow's discussion of the United States' contribution to the international cloud observations. It is a bulky volume of no less than 787 quarto pages.

Glancing at the first volume, attention is turned naturally to those points in which the practice of the United States Weather Office differs from that adopted in this country, and the first point to be noticed is that from March 1899 the period covered by the night forecasts was increased to forty-eight hours, and that the extension of period has worked successfully, whereas the limit of the British forecasts is twenty-four hours. It is true that the British Isles occupy a remarkably difficult position on a weather map. They are not only at the extreme west of Europe and catch the first effects of weather changes travelling eastward, but they are in a special manner the battle-field of the elements and are vexed with all the storms that belong to so-called temperate latitudes and western shores. These adverse circum stances in a British mind should provoke more daring enterprise rather than complacency with partial successes, yet we are still without telegraphic reports from Iceland, a recognised centre of atmospheric influence, and wireless telegraphy has not yet extended westward the available area of information.

The weather service in the United States is indeed a popular one. From a table in the report it appears that the total number of addresses in the United States supplied with forecasts and special warnings reached the astonishing figures of $24,467,106$. With these no British statistics can be compared.

It would require too much space to enter into details of the climatological data, which include, amongst other things, means of hourly readings at 28 stations. It should, however, be remarked that the year under review was noteworthy for the establishment of a number of stations for the storm-warning service in the West Indies at the conclusion of the war with Spain, and for the extensive system of aërial investigation by means of kites at 17 stations. This work was continued until the middle of November, 1898, by which time 1217 ascensions of 1000 feet and above had been made.

The second volume, written by Prof. F. H. Bigelow, is devoted exclusively to the cloud observations made in accordance with international agreement between May I, I895, and July I, I897. It is a very interesting and valuable contribution to the study of meteorology by observation of clouds, and the discussion is very fully carried out. The observations were of two kinds-theodolite observations at Washington, by which observers could determine the actual heights and velocities of individual clouds, and nephoscope observations at 15 stations in the United States from which velocities were estımated by the somewhat precarious method of assum-

United States Department of Agriculture. Report of the Chief of the ather Bureau. $1898-9$

$$
\text { NO. I } 647 \text {, VOL. 64] }
$$

ing the height of the particular type of cloud observed. The theodolite observations are printed in columns arranged according to the type of cloud observed, and occupy 93 pages of the volume. Their discussion leads directly to some very interesting results as to the variation of the velocities of clouds with height.

The nephoscope observations numbered some 23,000 . In order to coordinate them the whole United States area is first divided into six districts, and the position of each station for each observation with regard to a centre of high or low atmospheric pressure is identified by assigning it to one of twenty subsidiary areas within a circle of 1500 kilometres surrounding the centre of high or low pressure, as the case may be. In this way the distribution of velocity round the centres of "high" and "low" areas for each cloud level can be set out and the gradual change in distribution from the surface wind to the regular easterly march of the cirrus at about to kilometres height is traced.

In further discussion of the velocities at the different cloud levels, the general easterly drift at different levels is allowed for, and the residual vectors of velocity are plotted in diagrams to show the circulation components in "highs" and "lows" at the different cloud levels.

The same data enable the barometric gradients to be calculated, and the interesting results follow that the circulation phenomena are most vigorous in the middle group of cloud levels, viz. the Strato-cumulus to Altostratus group, and that there is no experimental evidence to show that there is an overflow of air from the upper part of a cyclonic area causing a higher pressure around it, as has been generally assumied.

The application of these results to the several districts of the United States in different typical states of weather is represented in 66 maps of the movement of the air at different levels over the United States. This completes the primary reduction of the observations. The remainder of the volume is occupied with the application of the inductive results obtained. First a section is devoted to the diurnal variation of the barometer. The diurnal variation of winds (taken from European stations) and of cloud motions at the alto cumulus, cirro cumulus and cirrus levels, taken from the cloud observations, is compared with the diurnal variation of magnetic force as part of a discussion of a possible relation between diurnal variation of barometric pressure and magnetic force. Without expressing an opinion upon Prof. Bigelow's own views, which have given rise to some controversy, it may be said that this discussion is very suggestive in view of the ideas which have recently been developed from Prof. Thomson's suggestion of "bodies smaller than atoms," Arrhenius and others, of the possible reception of particles from the sun carrying electrical charges which can move with the upper atmosphere.

Prof. Bigelow next deals with the general theory of atmospheric circulation in relation to the light thrown upon the subject by the cloud observations. He commences the discussion by a general review of his mathematico-meteorological troops. All the numerical, thermodynamical and hydrodynamical formulre available for meteorological warfare are paraded for inspection by the reader, and they are clothed in a new uniform on account of the need for a standard system of notation for meteorology. The uniform does not always quite fit. "Pounds $\times$ (foot $)^{2}$ " seems to require some sort of inversion before it can appropriately clothe pressure. But that is a small matter. The array of formulæ is very imposing, not to say repellent, and this part of meteorology needs a uniform that is less oppressive for the civilian meteorologist. But Prof. Bigelow's investigation moves generally upon sound lines. His criticism of Ferrel's solution of the problem of the local cyclone is sound, and his diagram (chart 69' representing the alternation of high and low areas as resulting from the play of pressure due to the action of two opposing streams of air is a very useiul representa- 
tion of the origin of the conspicuous barometric changes which are characteristic of middle latitudes.

The general scheme of Prof. Bigelow's contribution is to identify and describe the actual motion of the air. There is no doubt that the identification of the stream lines in the atmosphere is a most important step towards a dynamical theory of atmospheric phenomena. When these relations, which are, of course, strictly kinematical, have been satisfactorily established by observation and experiment, the transition to the dynamical explanation will be more practicable than any attempt to calculate the state of motion of the air a priori from assumed dynamical causes and conditions. The procedure from the observation and accurate identification of the actual motion, even if it be complicated, to the forces which produce it has for precedent the solution of the problem of planetary motion, and it is most interesting to see a similar process shaping itself in the less amenable department of winds and clouds.

Further applications of the observations are contained in chapters xii. to xiv., wherein the observations of cumulus and nimbus clouds, incorporated with kite and balloon observations, are used to throw light on the successive stages of change which take place in air as it rises from the surface ; and the reductions necessary for pressure and temperature to enable an observer, with the assistance of cloud observations, to draw up a weather map for the 3500 foot level or the 10,000 foot level are discussed, while in chapter xiv. the heat necessary to convert an "adiabatic atmosphere" into the atmosphere in its existing state is computed.

The latter part of the book is technical and based upon mathematical reasoning, and the style is by no means easy. The earlier part is observational, except that of course formulae are employed for reduction of the direction and magnitude of the motion of the clouds from the observed data. The whole work is admirably illustrated by large numbers of well executed charts upon which a great deal of the discussion is based.

It is too voluminous and important a work to criticise here in detail. What is most conspicuous about it is the easy coordination and correlation of so many different lines of meteorological research to form a definite idea of the real course of atmospheric changes. It is possible, and even probable, that the generalisations have gone a little further than the extent of the observations warrant at present, but the discussions show in what an important manner the general study of meteorology is affected by cloud measurements, and it suggests ideas which are certainly capable of confirmation, or possibly contradiction, by further observations. They make the reader feel that observations of the height and motions of the clouds are a matter, not merely of statistical interest, but may lead to the solution of most important problems in the physics of the atmosphere and may throw light even on the obscure phenomena of terrestrial magnetism.

The Weather Bureau is much to be congratulated upon the production of a volume at once so practical and so scientific amongst its official publications.

\section{A CANADIAN GEOLOGICAL EXPLORER.}

GOME few weeks back it was announced in NATURE

that Dr. Robert Bell, F.R.S., of Ottawa had been appointed director of the Geological Survey of Canada. It is an interestıng coincidence that Mr. Charles Hallock has recently written and dedicated to the National Geographical Society of Washington, D.C., a paper dealing with his explorations. This American recognition of a Canadian geological explorer is so remarkable that we desire to call attention to it, especially as it gives an idea of the new director's life work, the extensiveness of which will astonish many. Mr. Hallock, who has been acquainted with Dr. Robert Bell for thirty years, is only NO. I 647 , VOL. 64$]$ able to give us a very brief review of what has been accomplished by this exceptionally able and energetic geologist, for the account is a short one, but we feel that it is of such general interest that the following few facts may be stated.

Dr. Robert Bell commenced his career at fifteen. At that age, and in the year 1857 , he joined the Geological Survey under the late Sir W. E. Logan, then director, and served for three years as assistant to the principal members of the staff. Since then he has continued in the same work, but has acted as chief member of the various parties.

His surveys include portions of nearly every part of Canada. Beginning in the east, they comprise the "Gaspé Peninsula from Percé to Rimouski and from the St. Lawrence to the Baie des Chaleurs, and thence to Quebec, the eastern townships, the Saquenay and Lake St. John Region, the north shore of the Gulf of St. Lawrence, the west coast and the interior of Newfoundland and parts of Nova Scotia and New Brunswick." Dr. Bell has coasted round the eastern, or Atlantic, the northern and the western coasts of the Labrador peninsula, and also round some of the islands lying off the the coast. He has calculated that the peninsula is 560,000 English square miles, a region greater than the combined areas of Great Britain and Ireland, France, Germany, Belgium and Holland.

In the summer of 1897 he visited Baffinland and surveyed most of its southern coast, besides exploring the interior, where there are many large lakes. It is worth mentioning here that only one of these lakes had before been seen by a white man. This great island of Baffinland is I000 miles in length, and is only exceeded by Greenland and Australia in size.

The large island at the north end of Hudson Bay he has also explored, and has surveyed to a great extent the whole of the east coast of the Bay, from the Straits to the head of James Bay, also parts of the west coast of this vast inland sea, which was termed by him "the Mediterranean of North America."

Surveys have been made of the rivers flowing into James Bay. The Noddaway is the largest, and its great west tributary has been named the Bell River, after attention had been drawn to it by this eminent explorer. The rivers flowing into the Hudson Bay which he has surveyed comprise the Hayes, Steel and Hill, the great Nelson, with some of its tributaries, which drains the country as far as the Rocky Mountains, and the Great and Little Churchill rivers.

Coming further south we find his work comprises the Ottawa River from source to mouth, with its great tributary the Gatineau, and various neighbouring streams, the Montreal River and country north and south of it, and the country north of Lake Huron, including a great number of rivers and the mining district of Sudbury. The lake-peninsula of Ontario has been geologically examined by him, while he has surveyed the rivers on the north side of Lake Ontario, the Nipigon Lake, which is the most northern of the great lakes of the St. Lawrence, and also the rivers and their lakes and the country north of this to the Albany.

To the west of Lake Superior the wooded country to the prairies has been explored, and the international boundary line from this lake to the Lake of the Woods geologically examined by him. In I88I he published a map of this last-named lake, the first ever made.

Still further west a track-survey of most of the shores of Lake Winnipeg was completed. Lake Manitoba was explored, and, further west still, the Assinniboine, Swan and Qu'Appelle Rivers and extensive portions of the North and South Saskatchewan River. A good tracksurvey has, further, been made of Lac la Biche and its river as far as the Athabasca River, and also of that river itself as far north as the Athabasca Lake. 